\title{
Экспертиза
}

ТУЗОВА Светлана Юрьевна - кандидат химических наук, начальник отдела научно-технического сопровождения экспертизы Фонда информационного обеспечения науки (123557, Россия, г. Москва, ул. Пресненский Baл, 19, стр. 1; touzоva2000@таil.ru)

МИРОНОВА Яна Сергеевна - специалист отдела научно-технического сопровождения экспертизы Фонда информационного обеспечения науки (123557, Россия, г. Москва, ул. Пресненский Baл, 19, cmp. 1; miryana1@yandex.ru)

\section{НАУЧНО-ТЕХНИЧЕСКАЯ ЭКСПЕРТИЗА КАК ИНСТРУМЕНТ РЕАЛИЗАЦИИ ГОСУДАРСТВЕННОЙ ПОДДЕРЖКИ НАУЧНО- ТЕХНИЧЕСКОЙ ДЕЯТЕЛЬНОСТИ}

\begin{abstract}
Аннотация. Научно-техническая экспертиза является инструментом регулирования инновационной деятельности государства, целевого расходования бюджетных средств, выделяемых на поддержку научных исследований, и, следовательно, ее организация и компетентность имеют первостепенное значение. $B$ свою очередь эффективность научно-технической экспертизы во многом зависит от информационной поддержки организаторов, позволяющей экспертам проводить комплексную оценку проектов. Целью данной статьи является обзор технологий информационной поддержки работы эксперта в российской и зарубежной программах. В статье рассматриваются различные формы и методы информационной поддержки экспертов, а также их применимость на различных этапах экспертизы. Анализ методов информационной и аналитической поддержки экспертизы научно-технических проектов проводится на примере российской федеральной целевой программы «Исследования и разработки по приоритетным направлениям развития научно-технологического комплекса России на 2014-2020 годы» и зарубежных программ Horizon 2020 и Erasmus +.
\end{abstract}

Ключевые слова: федеральная целевая программа, ФЦП, субсидия, конкурс, научно-техническая экспертиза, проект

$\mathrm{C}$ воей задачей в области развития науки и технологий Россия ставит обеспечение к 2020 г. мирового уровня научных исследований и глобальной конкурентоспособности Российской Федерации на направлениях, определенных национальными научно-технологическими приоритетами, что закреплено в Стратегии инновационного развития ${ }^{1}$ и Концепции долгосрочного социальноэкономического развития Российской Федерации на период до 2020 года2 2

По объему ассигнований на исследования и разработки из средств государственного бюджета Россия является одним из мировых лидеров (по данным 2015 г. - 34,98 млрд долл. США), имея впереди себя только США (137,17 млрд долл.). Далее следуют Германия (33,02 млрд долл.), Япония (32,79 млрд долл.) и Франция (17,29 млрд долл.). За последние годы Россия повысила свой рейтинг среди стран ОЭСР по величине указанных ассигнований (млрд долл. США в расчете по паритету покупательной способности национальных валют) с 10-й позиции (13,2 млрд долл. в 2005 г.) до 4-й позиции (26 млрд долл. в 2010 г.) $)^{3}$.

Одним из способов финансирования научных проектов является программно-

1 Распоряжение Правительства РФ от 08.12.2011 № 2227-р «Об утверждении Стратегии инновационного развития Российской Федерации на период до 2020 года». Доступ: http://base.garant. $\mathrm{ru} / 70106124 /$

2 Распоряжение Правительства РФ от 17 ноября 2008 г. № 1662-р «О Концепции долгосрочного социально-экономического развития РФ на период до 2020 года». - Собрание законодательства РФ. 24.11.2008. № 47. Ст. 5489.

3 Войнилов Ю.Л., Городникова Н.В., Гохберг Л.М. и др. 2017. Индикаторы науки 2017: статистический сборник. М.: НИУ ВШЭ. С. 267-268. 
целевое финансирование, в рамках реализации которого решается целый комплекс социально-экономических и организационных задач: поддержка собственно актуальных направлений научных исследований, подготовка по ним кадров, обеспечение доступа к научным электронным ресурсам, обновление приборной базы научных организаций и стимулирование участия промышленного сектора в реализации результатов НИОКР/ПНИР.

Программно-целевое финансирование предусматривает создание особого организационно-процедурного механизма, позволяющего на конкурсной основе выбирать для государственной поддержки наиболее перспективные проекты [Черных, Миндели 2009].

Отбор проектов НИОКР/ПНИР осуществляется на основе результатов экспертизы проектов, к которой привлекаются наиболее опытные и высококвалифицированные эксперты, что позволяет значительно повышать эффективность использования средств федерального бюджета, направляемых на выполнение исследований и разработок. Экспертная оценка предлагаемого для поддержки проекта проводится на основе анализа актуальности и новизны предлагаемых технических решений проекта, обоснованности методов достижения запланированных результатов, квалификации и опыта работы коллектива исполнителей, их материально-технической базы и соответствия финансового обеспечения проекта планируемым работам [Каширин, Тихонов, Грачев 2015; Васильев 2001; Викулов, Бухарин, Дивуева 2014].

Экспертиза инновационных проектов играет ключевую роль в государственной научно-технической политике и позволяет формировать конкурентоспособные на мировом рынке материалы и технологии в связи с тем, что на всех этапах проекта - от конкурсного отбора до окончания работ по проекту - экспертиза позволяет не только отобрать наиболее перспективные научно-технологические проекты, спрогнозировать вероятность развития работ по проекту и найти причины возникновения риск-факторов, но также в случае возникновения при проведении работ по проекту непредвиденных научных/технологических осложнений предложить варианты исправления сложившейся ситуации и минимизировать негативные последствия. К таким риск-факторам нереализации проекта могут относиться: некомпетентность исполнителей, некорректное применение приборов и технологий, недостатки сырья или материалов, риски загрязнения окружающей среды или нанесения вреда здоровью человека проведением работ по проекту, нарушение плана выполнения работ, физическая недостижимость заявленных характеристик конечного продукта разработки и др.

Таким образом, именно научно-техническая экспертиза является инструментом регулирования целевого расходования бюджетных средств, выделяемых на поддержку научных исследований, и, следовательно, ее организация, компетентность и информационная поддержка имеют первостепенное значение.

На настоящий момент развитие информационных технологий, сложность критериев оценки проектов и изобилие научной информации обусловливает для экспертов при проведении экспертизы научно-технологических проектов необходимость искать, систематизировать и анализировать большой объем справочных материалов. Для облегчения работы экспертов в направлении сбора и систематизации научно-технической информации из открытых и внутренних баз данных организаторы экспертизы принимают ряд мер по методической и информационно-аналитической поддержке экспертов.

Подобная информационная поддержка экспертизы в зависимости от конкретного фонда или программы реализуется в различных направлениях. В данном контексте представляется целесообразным сравнить организацию инфор- 
мационной поддержки научно-технической экспертизы в России и за рубежом, например по таким значимым зарубежным программам научного финансирования, как Horizon $2020^{1}$ и Erasmus +2 , первая из которых охватывает проекты по развитию научных исследований и технологий, а вторая - проекты в рамках сотрудничества в области образования, профессионального обучения, молодежи и спорта и развития связей между высшим образованием и обществом.

Информационная поддержка экспертов сводится к следующему: непосредственно перед проведением экспертизы новые эксперты, еще не имеющие опыта экспертизы по программе, приглашаются для проведения инструктажа в офис Еврокомиссии в Брюссель, где ответственные организаторы разъясняют им алгоритм проведения экспертизы и механизмы оценки, а также проводят представление ИТ-инструмента, с помощью которого эксперты и проводят экспертизу проектов. Эксперты закрепляют полученную информацию путем тренировочной оценки специально подготовленных модельных проектных предложений, чем обеспечивается правильное понимание и интерпретация критериев оценки. Для экспертов, имеющих опыт экспертизы по программам, проводится вебинар, где их знакомят с внесенными в систему экспертиз изменениями и новыми конкурсными требованиями. Поддержка собственно на этапе экспертизы проводится как с помощью специализированного программного модуля, так и организаторами экспертизы.

Данный программный модуль на портале подачи электронных заявок позволяет обнаружить и идентифицировать:

- заявки из стран, не имеющих права на участие в соответствии с национальными и региональными приоритетами программ;

- заявки, в которых число вузов-исполнителей из стран программы и странпартнеров не соответствует требованиям конкурсов;

- вузы (организации высшего образования), не подписавшие ECHE (Erasmus Charter for Higher Education - устав Erasmus о высшем образовании);

- связь дочерних предприятий с организацией-партнером в заявке;

- проекты организаций-исполнителей или команд, выполненные за предыдущие годы.

В случае обнаружения программным модулем каких-либо проблем в материалах конкурсного предложения или отчетных материалах по проекту систематизированные данные передаются для анализа экспертам.

Каждого эксперта курирует организатор экспертизы и ведущий (опытный) эксперт, к которым в случае необходимости можно обратиться по электронной почте за консультацией. Также для экспертов предусмотрено участие в экспертном сообществе в закрытой группе на специализированной платформе, аналоге Facebook и ВКонтакте, используемой в качестве средства для общения, обмена информацией и разрешения различных вопросов по экспертизе. В каждой закрытой группе эксперты могут скачать необходимые для работы инструкции, справочные материалы и записи вебинаров.

Следует также отметить, что все отчетные материалы по поддержанным проектам при их загрузке на портал экспертиз исполнителями автоматически проходят проверку на наличие некорректных заимствований с тем, чтобы исполнители изначально имели возможность проследить наличие в их документах заимствований и загрузить при необходимости скорректированную версию документов. Таким образом, эксперты получают на экспертизу документы с отсутствием некорректных заимствований.

\footnotetext{
${ }^{1}$ https://ec.europa.eu/programmes/horizon2020/

2 https://eacea.ec.europa.eu/erasmus-plus_en
} 
В рамках данного вида экспертизы по указанным зарубежным программам подразумевается, что для вынесения оценки по актуальности и новизне тематики проекта, кроме предоставляемых организаторами сведений о проектах организаций-исполнителей/команд, выполненных за предыдущие годы, эксперт может самостоятельно ознакомится с публикациями/патентами по конкретному тематическому направлению в общедоступных информационных базах данных сети Интернет.

Другая ситуация с информационной поддержкой научно-технической экспертизы существует в рамках отечественной федеральной целевой программы «Исследования и разработки по приоритетным направлениям развития научнотехнологического комплекса России на 2014-2020 годы» ${ }^{1}$ (далее - Программа).

Следует отметить, что целью данной Программы является формирование конкурентоспособного и эффективно функционирующего сектора прикладных научных исследований и разработок. На эти цели из федерального бюджета на федеральную целевую программу «Исследования и разработки по приоритетным направлениям развития научно-технологического комплекса России на 2014-2020 годы» в 2017 г. было выделено 19,06 млрд руб. на научные исследования, что составило 5,63\% общего объема ассигнований на гражданскую науку из средств федерального бюджета в Российской Федерации за 2017 г. (338,7 млрд руб.).

Доля участия федеральной целевой программы «Исследования и разработки по приоритетным направлениям развития научно-технологического комплекса России на 2014-2020 годы» в общем объеме ассигнований на гражданскую науку в период с 2014 по 2016 г. составила 4,62\%, 4,87\%, 5,27\% соответственно, что говорит о значительной доле бюджетного финансирования Программы ${ }^{2}$.

В рамках Программы ${ }^{3}$ реализуются различные направления информационноаналитической поддержки экспертизы: поддержка по вопросам использования ресурсов «Системы экспертиз» 4 , методическая поддержка экспертов при проведении экспертизы, поддержка в использовании научно-информационных источников сети Интернет. Различны также и формы поддержки экспертизы по Программе: это текстовые инструкции и программные модули, позволяющие проводить техническую информационно-аналитическую работу по анализу объекта экспертизы; консультации кураторов и текстовые инструкции, а также вебинары, семинары, мастер-классы и круглые столы, направленные на углубление уровня экспертов во владении информационными ресурсами «Системы экспертиз» и базами данных сети Интернет. Эксперту также предоставляются различные справки, относящиеся непосредственно к тематике объекта экспертизы:

- справка из Федеральной системы мониторинга результативности деятельности научных организаций, выполняющих научно-исследовательские, опытно-конструкторские и технологические работы ${ }^{5}$, позволяющая эксперту оценить направление деятельности организации-заявителя и ее научно-технологическую результативность;

\footnotetext{
1 Постановление Правительства РФ от 21.05.2013 г. № 426 «О федеральной целевой программе “Исследования и разработки по приоритетным направлениям развития научно-технологического комплекса России на 2014-2020 годы”». Доступ: http://base.garant.ru/70385450/

2 Войнилов Ю.Л., Городникова Н.В., Гохберг Л.М. и др. 2017. Индикаторы науки 2017: статистический сборник. М.: НИУ ВШЭ. С. 66.

3 http://fcpir.ru

4 Система экспертиз - информационная система, предназначенная для хранения и анализа информации о ходе реализации Программы и обеспечивающая проведение независимой экспертизы в режиме удаленного доступа онлайн в формате 24 часа в сутки и 7 дней в неделю. См.: https://sstp.ru

5 www.sciencemon.ru
} 
- справка из Единой государственной информационной системы учета результатов научно-исследовательских и опытно-конструкторских работ гражданского назначения ${ }^{1}$, выполняемых за счет средств федерального бюджета, позволяющая эксперту оценить опыт участия организации и ключевых исполнителей проекта в выполнении НИР, ПНИР и ОКР;

- справка сетевого издания «Информационный ресурс СПАРК» ${ }^{2}$ международной информационной группы «Интерфакс» для проверки контрагентов и управления рисками, позволяющая эксперту оценить финансовые показатели организации - головного исполнителя проекта, его соисполнителя и индустриального партнера;

- справка по направлению исследований для оценки публикационной/ патентной активности по конкретному тематическому направлению в мире и в России, а также публикационной/патентной активности головного исполнителя, его соисполнителей, индустриального партнера и ключевых исполнителей проекта, сформированная по данным платформы Web of Science, патентной базы данных Orbit и других источников.

Экспертиза в рамках Программы осуществляется при помощи специального программного продукта «Система экспертиз» [Гарина и др. 2016а; 2016б; 2016в].

В «Систему экспертиз» встроено несколько специализированных программных модулей, агрегирующих и систематизирующих данные из различных информационных источников (ФИПС, РГБ, e-library, различные ФЦП, РФФИ и др.), которые позволяют анализировать полученную информацию, в т.ч. с применением методов визуализации (построение диаграмм, графиков и т.п.).

Одним из таких модулей является модуль интеграции источников научнотехнической информации, задачей которого является формирование информационной среды обмена данными. Данный модуль агрегирует и систематизирует тематическую информацию по статьям, патентам, диссертациям, конкурсным заявкам и поддержанным некоторыми фондами проектам. Таким образом, в сжатые сроки эксперт может проанализировать систематизированную из различных наукометрических баз информацию по тематике заявки/проекта, оценить информационную среду направления исследований и участие исполнителей и организации-заявителя, его соисполнителя и индустриального партнера в работах по данному тематическому направлению.

Кроме вышеуказанного модуля интеграции научно-технической информации, имеется также и модуль анализа заимствований, основными задачами которого является выявление повторяющихся тематик заявок (для предотвращения повторного финансирования проектов), а также обнаружение прямых и косвенных заимствований в тексте отчетных материалов по проектам.

Систематизированная и визуализированная с помощью данного модуля информация позволяет независимому эксперту оценить проект с точки зрения его новизны и оригинальности, отследить и проверить наличие заимствований из ранее поддержанных в рамках Программы проектов, а также опубликованных статей, материалов диссертаций, патентных документов и др. источников, имеющихся в наполнении данной базы.

Таким образом, возможности «Системы экспертиз» и ее специализированных информационно-аналитических модулей способствуют проведению экспертом многостороннего критического анализа объекта экспертизы и вынесению объективной оценки по различным критериям [Тузова, Дивненко 2016; Зеленцова и др. 2017; Тузова 2017].

\footnotetext{
${ }^{1}$ http://rosrid.ru

2 www.spark-interfax.ru
} 
В рамках Программы осуществляются и другие формы информационной поддержки экспертов - вебинары, семинары, мастер-классы и круглые столы, направленные на углубление уровня экспертов во владении информационными ресурсами «Системы экспертиз» и базами данных сети Интернет. Как видно из изложенного выше, консультационная и информационно-аналитическая поддержка научно-технической экспертизы в рамках Программы является разносторонней и многообразной, что, несомненно, положительно сказывается на качестве проводимой экспертизы благодаря выработке у экспертов необходимых навыков при проведении экспертизы, владению программными ресурсами, внешними информационными ресурсами, а также обмену мнениями с целью получения предложений по улучшению программного обеспечения и совершенствованию сопровождения научно-технической экспертизы. Результатом проводимых многоплановых работ по информационной поддержке научнотехнической экспертизы в рамках Программы является повышение эффективности расходования бюджетных средств на выполнение прикладных научных исследований и направление государственного финансирования на поддержку проектов, результаты работ по которым могут быть доведены до промышленного освоения и в перспективе окупить государственные вложения налоговыми отчислениями в бюджет.

\section{Список литературы}

Васильев И.А. 2001. Анализ эффективности инвестиционных проектов. М.: ВЕДИ. 208 с.

Викулов О.В., Бухарин С.Н., Дивуева Н.А. 2014. Типовой технологический процесс проведения научно-технической экспертизы, реализованный в ФГБНУ НИИ РИНКЦЭ. - Инноватика и экспертиза: научные труды. № 2(13). C. 101-114.

Гарина С.М., Тузова С.Ю., Лазаренко Н.Е., Антипов Е.Е. 2016а. К вопросу о подготовке заявок на получение субсидии в рамках ФЦП «Исследования и разработки по приоритетным направлениям развития научно-технологического комплекса России на 2014-2020 годы». - Альтернативная энергетика и экология. № 11-12. С. 104-110.

Гарина С.М., Тузова С.Ю., Лазаренко Н.Е., Антипов Е.Е. 2016б. Анализ причин отклонения заявок на получение субсидии в рамках ФЦП «Исследования и разработки по приоритетным направлениям развития научно-технологического комплекса России на 2014-2020 годы». - Химическая технология. № 3. C. $140-144$.

Гарина С.М., Тузова С.Ю., Лазаренко Н.Е., Антипов Е.Е. 2016в. О подготовке заявок на получение субсидии в рамках ФЦП «Исследования и разработки по приоритетным направлениям развития научно-технологического комплекса России на 2014-2020 годы». - Вопросы материаловедения. № 2(86). С. 189-190.

Зеленцова Н.И., Петров А.Н., Гарина С.М., Тузова С.Ю. 2017. Об экспертном рассмотрении заявок на получение бюджетного финансирования в рамках ФЦП «Исследования и разработки по приоритетным направлениям развития научно-технологического комплекса России на 20142020 годы». - Инновации. № 2(220). С. 86-92.

Каширин В.В., Тихонов Г.В., Грачев Н.Н. 2015. Основы методологии оценки и критериев отбора лучших инновационных проектов. - Экономика и управление в машиностроении. № 1. С. 48-52.

Тузова С.Ю., Дивненко О.В. 2016. Оптимизация подходов к научно-технической экспертизе конкурсных заявок на получение государственной субсидии. МИР (Модернизация. Инновации. Развитие). Т. 7. № 4(28). С. 194-198. 
Тузова С.Ю. 2017. Использование наукометрических баз данных при экспертизе научно-технических проектов. - Электронные библиотеки. Т. 20. № 6. C. 450-458.

Черных С., Миндели Л. 2009. Проблемы финансирования российской науки. - Общество и экономика. № 1. С. 129-142.

TUZOVA Svetlana Yur'evna, Cand.Sci. (Chem.), Head of the Department of Scientific and Technical Examination, Foundation for Information Support of Science (bld. 1, 19 Presnenskiy Val St, Moscow, 123557, Russia; touzova2000@ mail.ru)

MIRONOVA Yana Sergeevna, Specialist of the Department of Scientific and Technical Examination, Foundation for Information Support of Science (bld. 1, 19 Presnenskiy Val St, Moscow, 123557, Russia; miryana1@yandex.ru)

\title{
SCIENTIFIC AND TECHNICAL EXPERTISE AS AN INSTRUMENT FOR THE IMPLEMENTATION OF STATE SUPPORT FOR SCIENTIFIC AND TECHNOLOGICAL ACTIVITIES
}

\begin{abstract}
Scientific and technical expertise is an instrument for regulating the innovation activity of the state, regulating the targeted spending of budget funds allocated to support of scientific research and, therefore, its organization and competence are of paramount importance. In turn, the effectiveness of scientific and technical expertise largely depends of the information support of the organizers. Multilateral informational support allows experts to conduct a comprehensive assessment of the projects. The purpose of this article is to review the technologies of information support for the expert's work in Russian and foreign programs. Various forms and methods of information support for experts, as well as their applicability at various stages of the examination, are discussed in the article. The analysis of methods of information and analytical support for the examination of scientific and technical projects is conducted on the example of the Russian federal target program «Researches and Developments in Priority Directions of Scientific and Technological Complex of Russia for 2014-2020» and foreign programs Horizon 2020 n Erasmus +.
\end{abstract}

Keywords: federal target program, FTP, subsidy, competition, scientific and technical expertise, project 